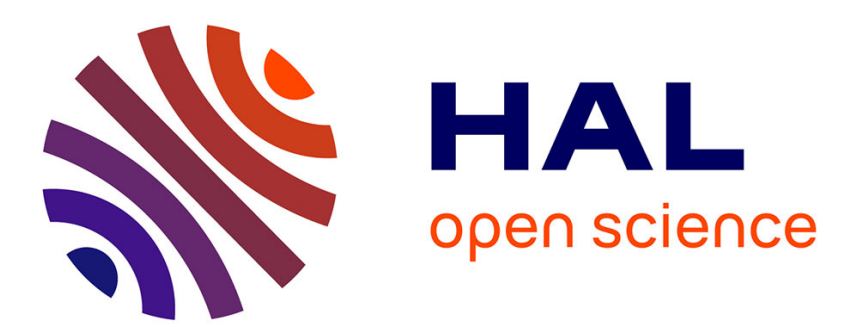

\title{
Proceedings of the GDR Vertige 2019 annual meeting devoted to endolymphatic hydrops
}

Christian Chabbert, Anne Charpiot

\section{To cite this version:}

Christian Chabbert, Anne Charpiot. Proceedings of the GDR Vertige 2019 annual meeting devoted to endolymphatic hydrops. Journal of Vestibular Research, 2021, 31 (4), pp.243-245. 10.3233/VES200797 . hal-03430477

\section{HAL Id: hal-03430477 https://hal.science/hal-03430477}

Submitted on 16 Nov 2021

HAL is a multi-disciplinary open access archive for the deposit and dissemination of scientific research documents, whether they are published or not. The documents may come from teaching and research institutions in France or abroad, or from public or private research centers.
L'archive ouverte pluridisciplinaire HAL, est destinée au dépôt et à la diffusion de documents scientifiques de niveau recherche, publiés ou non, émanant des établissements d'enseignement et de recherche français ou étrangers, des laboratoires publics ou privés. 


\title{
Proceedings of the GDR Vertige 2019 annual meeting devoted to endolymphatic hydrops
}

\author{
Christian Chabbert ${ }^{\mathrm{a}, *}$ and Anne Charpiot ${ }^{\mathrm{b}, \mathrm{c}}$ \\ ${ }^{a}$ Aix Marseille University-CNRS, Laboratory of Cognitive Neurosciences, UMR7291, \\ Team Pathophysiology and Therapy of Vestibular Disorders, Marseille, Unit GDR2074 CNRS, France \\ ${ }^{\mathrm{b}}$ Strasbourg University Hospital, department of ENT, France \\ ${ }^{\mathrm{c}}$ ICube, UMR 7357, Team biomecanics, Strasbourg, France
}

\begin{abstract}
The GDR Vertige is a federative research group gathering the different components of the French neuro-otology community. The annual meeting of the GDR Vertige is an opportunity for interactive exchanges between scientists, clinicians and industrialists, on basic issues related to vestibular function, as well as translational questions regarding the management of vestibular disorders. For its fifth edition, the annual meeting of the GDR Vertige, which took place in September 2019 in Marseille (France), was devoted to one of the most peculiar phenomena of neuro-otology: endolymphatic hydrops. For two days, international scientists and clinicians presented the most recent advances regarding the biophysical correlates of endolymphatic hydrops, the genetic and endocrine tableaux that favor its manifestation, new methods of clinical imaging, and current and upcoming therapeutic strategies to overcome the associated clinical manifestations. This special issue of the Journal of Vestibular Research aims at providing the proceedings of this meeting.
\end{abstract}

\section{GDR vertige}

The Groupement de Recherche sur le Vertige (GDRV; research group on vertigo) was created in 2015 in order to bring together the French neurootology community, to shed light on the research and clinical teams involved in the research on the pathophysiology and therapies of vestibular disorders, and to stimulate the development of multidisciplinary research projects. For five years, the GDRV has been developing continuous training action for young scientists and practitioners through a thematic school that takes place every year in July. An annual meeting also takes place every year in September (for more information see http://gdrvertige.com).

\footnotetext{
*Corresponding author: C. Chabbert, Aix Marseille UniversityCNRS, Laboratory of Cognitive Neurosciences, LNC UMR 7291. Team Pathophysiology and Therapy of Vestibular Disorders, 3 Place Victor Hugo, 13331 Marseille Cedex 3, France. E-mail: christian.chabbert@univ-amu.fr.
}

\section{Annual meeting of the GDRV}

The annual Meeting of the GDRV brings together once a year multidisciplinary actors (clinicians, researchers, physiotherapists, orthoptists and industrialists) of the French and French-speaking neurootology community. During two days, various events such plenary conferences, round tables, workshops, and exhibitions are organized with the aim of promoting exchanges and collaborations around major questions regarding research on vestibular function, vestibular pathophysiology, and care of the dizzy patients. The organization of the annual GDRV Meeting is supported by a multidisciplinary organization committee. The successive meetings since 2015 have focused on the following topics: "How to innovate in Neuro-otology", "Peripheral insult: etiology, diagnosis, therapy", "Cognition and Vertigo: from basics to therapeutic applications" and "Vestibular compensation: from basic research to therapeutic 
applications". For its fifth meeting, the annual twoday meeting of the GDRV that took place September 2019 in Marseille (France) was devoted to endolymphatic hydrops. Scientists and clinicians from USA, Switzerland and Italy joined the French community at this meeting.

\section{What is new regarding endolymphatic hydrops?}

Since the first histopathological observations of swelling of the endolymphatic compartment, associated with atrophy of both the cochlea and vestibule provided in 1939 by Hallpike and Cairns, our knowledge about the functional consequences of this tissue damage has progressed very little. Many questions remain about the role of hydrops in the generation of Meniere Disease (MD) symptoms and their evolution over time. In the first paper of this special issue, $\operatorname{Pr}$ A CHARPIOT from the Strasbourg University Hospital (France) summarizes the main clinical signs of Meniere's Disease and the different observations that support the association between the expression of the symptoms and the notion of endolymphatic hydrops. Endolymphatic hydrops and cochleo-vestibular symptoms have to be considered with a focus on their dynamics. Precise descriptions of the duration and sequence of signs during the characteristic spells now make sense based on knowledge about inner ear physiology.

\subsection{New methods for imaging the endolymphatic hydrops in vivo}

The first images revealing the tissue consequences of endolymphatic hydrops were obtained more than 80 years ago on histopathological samples. Over the last decade, application of MRI techniques provided the first in vivo images of endolymphatic hydrops. The use of contrast solutions (such as gadolinium) allowing clear distinction between perilymph and endolymph is the latest step allowing identification of areas preferentially exposed to swelling in the endolymphatic compartment. This technological advance also makes it possible now to correlate more precisely the different symptoms of Meniere's Disease to structural damages affecting the different inner ear compartments. It also raises new questions related to the existence of endolymphatic hydrops in non-symptomatic subjects. Pr F VEILLON from the Strasbourg University Hospital, and Dr M ELIEZER from the University Hospital of Lariboisière in Paris, give an overview of the recent advances in the medical imaging of endolymphatic hydrops, highlighting the limits of the current approaches, and the steps toward the improvement of inner ear imaging. Through an in vivo imaging approach of the inner ear in a mouse model of blast injury, Pr JS OGHALAI from the Center for Health Professions at the University of Southern California in Los Angeles (USA), reveals that endolymphatic hydrops can be generated after blast injury. The data presented provide consistent evidence that the volume of the endolymph can be modulated by the osmotic gradient between the endolymph and the perilymph.

\subsection{Biophysical aspects of the generation of the endolymphatic hydrops}

Although the physical characteristics of the inner ear liquid compartments are well defined and the laws of diffusion of ions or small molecules in liquids have long been mastered, only partial information is available on fluid exchanges between the different inner ear compartments. This mainly results from the lack of knowledge about the molecular effectors involved in the ion exchange and fluid flows between perilymph and endolymph. In this special issue, $\mathrm{Pr} \mathrm{P}$ AVAN from the Clermont Ferrand University Hospital (France) go through the physical characteristics of the inner ear compartments, and the biophysical aspects of hydrops generation. Dr I DJENNAOUI from the Strasbourg University Hospital (France), through a parallel between the human pathology and animal models of endolymphatic hydrops, raises the interesting question of whether the Meniere's acute episodes are driven by pressure or volume events. Dr C CHABBERT from the Laboratory of Cognitive Neuroscience CNRS-AMU in Marseille (France) details the current knowledge on the molecular effectors expressed in the mammalian vestibule, which may support the ionic and liquid exchanges between perilymph and endolymph. He also refers to the "hydrostatic" and "hydrodynamic" theories proposed nearly 150 years ago by Friedrich Goltz and Joseph Breuer.

\subsection{Genetic and endocrine tableaux which favor the manifestation of endolymphatic hydrops}

Menière's Disease (MD) probably arises from the interplay of genetic and environmental factors. The maintenance of a proper fluid and ionic composition 
is determined by water channels (Aquaporins, widely studied in the last years), ionic transporters and biohumoral factors. In this special issue, Pr R TEGGI from the San Raffaele Scientific Institute in Milano (Italy) debates the role of ionic exchangers and regulating factors in the pathophysiology of MD. He especially focuses on genes such as SIKI (rs3746951) and SLC8A1 (rs487119), for which the expression is significantly modulated in MD patients, and on the endogenous ouabain whose plasma levels is also increased in MD patients.

\subsection{Endolymphatic hydrops and neurological disorders}

Another paper, from Dr REDON and colleagues from the Marseille University Hospital (France) reviews literature related to the presence of endolymphatic hydrops in some neurological disorders. For some of these disorders, which are related to a cerebrospinal fluid pressure imbalance, the author highlights the interest of a non-invasive assessment of endolymphatic hydrops for diagnosis and follow-up.

\subsection{Menière's disease \& endolymphatic hydrops: open questions and possible answers}

A paper from Dr S HEGEMANN (Zurich University, Switzerland) provides a new hypothetical explanation for major unresolved questions of etiopathology and pathophysiology of MD, being so far unexplained and not completely understood. The suggested hypothesis explains the close connection of MD and Migraine, the coexistence of endolymphatic hydrops and Menière attacks, as well as the detected signs of inflammation in the inner ears of MD patients.

\subsection{Pendred: A congenital hydrops?}

Dr SIMON (ENT Department, Necker-Sick children's Hospital and INCC University of Paris, France) discusses the parallels between Menière disease and SLC26A4 congenital diseases (ie: Pendred syndrome/DFNB4), which are both inner ear disorders with fluctuating and progressive hearing loss associated with endolymphatic hydrops. Exploring clinical and animal evidence, he presents the idea that Pendred/DFNB4 may be considered a form of fetal hydrops and that more communication should be formed between clinicians and researchers in both disorders.

\subsection{Clinical management of the hydrops}

The last article in this special issue is devoted to the clinical management of hydrops. Dr A WECKEL of the Purpan University Hospital of Toulouse (France) illustrates the difficulties encountered by clinicians in establishing a correct diagnosis of Meniere's disease on the basis of only clinical criteria, and the expectations of the ENT community toward high resolution inner ear MRI. Dr. Weckel also evokes the uncertainties of the therapeutic approach mainly based on conservative therapies, and in case of failure, on non-ablative or ablative therapies. The difficulties encountered are illustrated through a patient case.

\section{Conflict of interest}

The author declares no competing financial interests. 